\title{
Research and Publication Trends in Hospital Medicine
}

\author{
An N. Dang Do, MD, PhD¹, Amy M. Munchhof, MD, PhD*, Colin Terry, $\mathrm{MS}^{2}$, Thomas Emmett, MD, MLS ${ }^{3}$, Areeba Kara, MD4
}

${ }^{1}$ Internal Medicine-Pediatric Residency Program, Indiana University School of Medicine, Indianapolis, Indiana; ${ }^{2}$ Methodist Research Institute, Indianapolis, Indiana; ${ }^{3}$ Ruth Lilly Medical Library, Indiana University School of Medicine, Indianapolis, Indiana; 4 Inpatient Medicine Indiana University Health Physicians, Methodist Hospital, Indianapolis, Indiana.

BACKGROUND: Research by hospitalists may aid the evolution of hospital medicine into an academic specialty.

OBJECTIVE: To describe the factors associated with research and publication activities among hospitalists and describe trends in hospitalist-led publications.

METHODS: We surveyed members of the Society of Hospital Medicine in June 2012 and conducted univariate analyses on their responses to determine predictors of successful authorship and to describe factors associated with research engagement. We searched PubMed from the database inception to October 2013 for publications with "hospitalist" or "hospital medicine" affiliated authors. Original research articles were reviewed for methodology and funding sources.

RESULTS: Of the 645 respondents (5.8\% response rate), $277(43 \%)$ had authored peer-reviewed publications, 126 (19\%) had access to mentorship, and 68 (11\%) reported

In 1996, Wachter and Goldman heralded the arrival of hospitalists in the healthcare system. They recognized the need to link the clinical role of a hospitalist with other activities, both to provide a creative outlet and to assist in the creation of "research and development arms." 1 The explosive growth of hospital medicine followed, and hospitalists rapidly entered the mainstream of the healthcare system. ${ }^{2}$

A consensus conference in 2009 identified the challenges faced by hospitalists in conducting research as a key obstacle in the evolution of the profession into an academic field. ${ }^{3}$ Strategies for building and facilitating hospitalist research programs have been described. ${ }^{4-7}$ However, a survey of US academic hospitalist leaders found more than $40 \%$ feared their faculty was "not developing sustainable nonclinical activities." 8

Data describing research aspirations and support systems among hospitalists are sparse, and no previ-

*Address for correspondence and reprint requests: Amy M. Munchhof, MD, Internal Medicine-Pediatrics, Assistant Professor of Clinical Medicine, Indiana University School of Medicine. Academic Hospitalist Eskenazi Health Hospital, 720 Eskenazi Ave 5/3 Faculty Building Department of Medicine-Suite E2121, Indianapolis, IN 46202; Telephone: 317.880.8211; Fax: 317.880.0565; E-mail: amunchhof@gmail.com

Additional Supporting Information may be found in the online version of this article.

Received: September 9, 2013; Revised: November 20, 2013 and December 14, 2013; Accepted: December 17, 2013 2014 Society of Hospital Medicine DOI 10.1002/jhm.2148 Published online in Wiley Online Library (Wileyonlinelibrary.com). funding support. There were 213 (33\%) who were engaged in research, with the majority conducting quality improvement (QI) research $(n=152,24 \%)$. Completion of a fellowship, pediatrics training, the presence of a mentor, funding, and $>25 \%$ protected time for research were each individually associated with an increased likelihood of authoring publications. Hospitalist-led publications in PubMed have been increasing from 36 in 2006 to 179 in the first 10 months of 2013. Of the original research publications $(n=317)$, the majority were clinical $(n=129,41 \%)$, and $58(18 \%)$ were QI. Thirty-nine (22\%) authors reported funding support.

CONCLUSIONS: Peer-reviewed publications by hospitalists are increasing, suggesting the academic maturation of hospital medicine. Provision of mentorship for hospitalists specifically in QI and guidance toward funding resources may assist in supporting this trend. Journal of Hospital Medicine 2014;9:148-154. (C) 2014 Society of Hospital Medicine

ous study has described the trends in hospitalist publications. In this work we describe the current standing of hospital medicine research through a survey of both academic and non-academic hospitalists and a review of hospitalist-related publications.

\section{METHODS}

The Indiana University institutional review board approved this study.

\section{Survey of Hospitalists}

A 29-item questionnaire that addressed research activities, barriers, and mentorship was designed and piloted with pediatrics trainees at Indiana University. The final version (see Supporting Survey in the online version of this article) was approved by the Society of Hospital Medicine (SHM) research committee and posted on Zoomerang ${ }^{\circledR}$ (http://www.zoomerang.com). The survey was administered on June 1, 2012 via e-mail to a convenience sample of hospitalists identified through the SHM membership base. ${ }^{9}$ The survey remained open for 1 month; 2 email reminders were sent.

\section{Review of Publications}

A PubMed search was conducted on October 8, 2013 for records with either "hospital medicine" or "hospitalist" in the affiliation field. This field provides the departmental name and address information for the first author, except for the not-yet-indexed 
publisher-supplied records, which could include all author addresses. ${ }^{10}$ Editorials and letters to the editor were excluded, and results were limited to English. All resulting articles were manually curated and retained only if the affiliation criteria of "hospitalist" or "hospital medicine" (as a relevant single phrase) were associated with the first author. All articles meeting the criteria were reviewed by 1 of the authors and categorized as a review, a case report, or as original research (when methodology was described in the abstract). Original research articles were assigned a category based on their methodology and research type, as defined in published literature. The categories included basic sciences, clinical, health information, health services, quality improvement (QI), education, and translational research. ${ }^{11-15}$ If the article overlapped categories, a secondary category was also assigned. A second author independently evaluated a subset of articles. This subset was then used to calculate the overall concordance between the authors based on their agreement on either the primary or secondary category designations.

To capture data on research funding, each original research article was searched for statements directly linking the first author or the work to the funding source(s).

Publications in the Journal of Hospital Medicine (JHM) were reviewed to serve as a gauge of research interests in the field of hospital medicine that may not be reflected by the publications resulting from the PubMed search. JHM was selected as the journal best representing hospital medicine based on its stated mission of commitment to the advancement of the hospital medicine specialty. ${ }^{16}$ All original research articles in JHM were assigned a category by 1 of the authors based on the methodology in the abstract.

\section{Statistical Methods}

The survey responses were summarized using descriptive statistics. Univariate tests of association between respondent characteristics and peer-reviewed authorship were performed using the Fisher's exact test. $P$ values of $\leq 0.05$ were considered significant. Data from the publication searches were presented as descriptive statistics.

\section{RESULTS}

\section{Survey}

The survey link was emailed to 11,611 SHM members: 11,102 members received the link and 509 emails were returned as undeliverable. A total of 645 member responses were received (5.8\% response rate).

The most common demographic characteristics identified included male gender, age 45 or younger, and white race. The locations of the current practices were distributed equally across the United States. Over half of the respondents were trained in internal medicine, and a quarter were trained in pediatrics.
TABLE 1. Descriptive Characteristics of All Survey Respondents and Survey Respondents With Research Funding

\begin{tabular}{|c|c|c|c|c|}
\hline \multirow[b]{2}{*}{ Characteristics } & \multicolumn{4}{|c|}{ Responses, N (\%) } \\
\hline & \multicolumn{2}{|c|}{ All Responses } & \multicolumn{2}{|c|}{$\begin{array}{l}\text { Responses With } \\
\text { Funding }\end{array}$} \\
\hline Gender & 597 & & 67 & \\
\hline Female & & $248(41)$ & & $33(49)$ \\
\hline Male & & $349(58)$ & & $34(51)$ \\
\hline Age, y & 599 & & 67 & \\
\hline $25-35$ & & $157(26)$ & & $17(25)$ \\
\hline $36-45$ & & $274(46)$ & & $39(58)$ \\
\hline $46-55$ & & $105(17)$ & & $6(9)$ \\
\hline $56-65$ & & $56(9)$ & & $5(7)$ \\
\hline$>65$ & & $7(1)$ & & 0 \\
\hline Current practice location & 596 & & 67 & \\
\hline Midwest & & $147(25)$ & & $18(27)$ \\
\hline Northeast & & $113(19)$ & & $12(18)$ \\
\hline South & & $172(29)$ & & $14(21)$ \\
\hline West & & $142(4)$ & & $16(24)$ \\
\hline Other & & $22(34)$ & & $7(10)$ \\
\hline Race & 595 & & 67 & \\
\hline White & & $444(75)$ & & $58(87)$ \\
\hline Black & & $18(3)$ & & 0 \\
\hline Hispanic & & $22(4)$ & & $1(1)$ \\
\hline Asian & & 85 (14) & & $8(12)$ \\
\hline Other & & $26(4)$ & & \\
\hline Faculty appointment & 593 & & 68 & \\
\hline Nonacademic & & $221(37)$ & & $4(6)$ \\
\hline Instructor/lecturer & & $60(10)$ & & $6(9)$ \\
\hline Assistant professor & & $197(33)$ & & $32(47)$ \\
\hline Associate professor & & $68(11)$ & & 19 (28) \\
\hline Full professor & & $14(2)$ & & $4(6)$ \\
\hline Other & & $33(6)$ & & $3(4)$ \\
\hline Fellowship training & 68 & & 14 & \\
\hline General IM/hospitalist & & 15 (22) & & $6(43)$ \\
\hline Pediatric hospital medicine & & $7(10)$ & & $2(14)$ \\
\hline Other & & $46(68)$ & & $6(43)$ \\
\hline Residency completed & 616 & & 68 & \\
\hline IM & & $340(55)$ & & 36 (53) \\
\hline Pediatrics & & $154(25)$ & & $27(40)$ \\
\hline Family medicine & & $53(9)$ & & $1(1)$ \\
\hline IM/pediatrics & & $48(8)$ & & $2(3)$ \\
\hline Other & & $21(3)$ & & $2(3)$ \\
\hline
\end{tabular}

NOTE: $N$ represents the number of responses. Percentages calculated based on the total number of responses to the specific question. Abbreviations: IM, internal medicine.

Eleven percent had undertaken fellowship training after residency. Thirty-seven percent did not hold an academic rank, and among those who did, most were assistant professors. (Table 1)

Overall availability of mentorship was low, but respondents with academic appointments were more likely to have a mentor than those without academic appointments ( $32 \%$ vs $2.7 \%, p<0.001)$. Hospitalists most likely identified their own mentors, and meetings between the hospitalist and mentor occurred more frequently than once every 3 months.

There were $213(33 \%)$ respondents who identified themselves as currently conducting research, $96(45 \%)$ of whom were trained in pediatrics. Ninety-two 
$(28 \%)$ of those with academic appointments and 157 $(71 \%)$ of those without academic appointments had no current or future plans to engage in research. QI research, followed by clinical research, emerged as the most frequent type of research that hospitalists were either currently engaged in or planned to embark on. Most respondents identified factors other than age, family or financial issues, the grant process, or a lack of institutional support as the reason for not conducting research. (Table 2)

Sixty-eight $(10 \%)$ respondents held research funding, and 6 identified the grant process as an impediment to doing research. The most commonly reported funding source was from government and institutions, followed by support from foundations (see Supporting Figure $1 \mathrm{~A}$ in the online version of this article). Responders with research funding were predominantly young, white, and assistant or associate professors. Fourteen hospitalists with funding reported completing a fellowship. (Table 1)

More than half of the respondents $(\mathrm{n}=332)$ had not authored peer-reviewed publications. Of the 277 who had published successfully, 89 (31\%) were trained in pediatrics. For those with publications, 152 $(55 \%)$ reported publishing less than once per year. The type of article published most frequently was original research followed by case reports/series and reviews. (Table 2)

Variables individually associated with an increased likelihood of authoring peer-reviewed publications included the completion of a fellowship, having an academic appointment, the availability of funding and mentorship, a background of pediatrics training, and more than $25 \%$ dedicated research time. (Table 3 )

\section{Publications Review}

The PubMed search yielded 784 publications with "hospital medicine" or "hospitalist" in the affiliation field. After manual review, 660 articles were retained. (Figure 1)

The volume of hospitalist-led publications has been increasing. Between 2006 and October 2013 there was a 5 -fold increase in hospitalist-led publications (36 in 2006 to 179 in the first 10 months of 2013). Of the 660 articles culled from the PubMed search, $581(88 \%)$ represented the work of authors affiliated with adult hospital medicine; 266 (46\%) of these represented original research (the rest were reviews and case reports). Seventy-nine $(12 \%)$ of the 660 PubMed articles were related to pediatric hospital medicine; $51(65 \%)$ of these represented original research. (Figure 1) In the period studied there was a variation from year to year in the proportion of publications representing original research, with a range of $37 \%$ to $71 \%$ comprising original research in adult hospital medicine publications and $50 \%$ to $81 \%$ in pediatric hospital medicine publications (Figure 2A).
TABLE 2. Research and Publication Activities Reported by Surveyed Adult and Pediatric Hospitalists

\begin{tabular}{|c|c|c|c|}
\hline \multirow[b]{2}{*}{ Activity } & \multicolumn{3}{|c|}{ Responses, N (\%) } \\
\hline & Adult Medicine & \multicolumn{2}{|c|}{$\begin{array}{l}\text { Pediatric } \\
\text { Medicine }\end{array}$} \\
\hline $\begin{array}{l}\text { No plan to conduct research } \\
\text { Reasons for not doing research }\end{array}$ & 245 & 26 & \\
\hline Lack of institutional support & $42(17)$ & & $3(12)$ \\
\hline Family issues & $14(6)$ & & $1(4)$ \\
\hline Financial & $8(3)$ & & 0 \\
\hline Grant process & $4(2)$ & & $2(8)$ \\
\hline Age & $5(2)$ & & 0 \\
\hline Other & $171(70)$ & & $20(77)$ \\
\hline Currently doing research & 117 & 96 & \\
\hline Quality improvement & $79(68)$ & & $73(76)$ \\
\hline Clinical & $59(50)$ & & $62(65)$ \\
\hline Health services & $31(26)$ & & $30(31)$ \\
\hline Health informatics & $28(24)$ & & $11(11)$ \\
\hline Translational & $10(8)$ & & $7(7)$ \\
\hline Basic science & $3(3)$ & & 0 \\
\hline Other & $17(14)$ & & $10(10)$ \\
\hline Plan on doing research & 183 & 30 & \\
\hline Quality improvement & $72(39)$ & & $25(83)$ \\
\hline Clinical & $65(35)$ & & $25(83)$ \\
\hline Health services & $20(11)$ & & $2(7)$ \\
\hline Health informatics & $25(14)$ & & $3(10)$ \\
\hline Translational & $8(4)$ & & $3(10)$ \\
\hline Basic science & $3(2)$ & & 0 \\
\hline Other & $8(4)$ & & 0 \\
\hline Peer-review publications & 458 & 151 & \\
\hline № & $270(59)$ & & $62(41)$ \\
\hline Yes & $188(41)$ & & $89(59)$ \\
\hline \multicolumn{4}{|l|}{ Frequency } \\
\hline Less than once/year & $111(59)$ & & $41(46)$ \\
\hline Once/year & $22(12)$ & & 20 (22) \\
\hline Twice/year & $16(8)$ & & $16(18)$ \\
\hline More than twice/year & $23(12)$ & & $10(11)$ \\
\hline Other & $13(7)$ & & $1(1)$ \\
\hline \multicolumn{4}{|l|}{ Publication Type } \\
\hline Original research & $97(52)$ & & $75(84)$ \\
\hline Case reportseries & $80(42)$ & & $41(46)$ \\
\hline Reviews & $63(34)$ & & $25(28)$ \\
\hline Clinical trials & $36(19)$ & & $9(10)$ \\
\hline Practice guidelines & $18(10)$ & & $12(13)$ \\
\hline Meta-analysis & $14(7)$ & & $8(9)^{\prime}$ \\
\hline Other & $23(12)$ & & 0 \\
\hline
\end{tabular}

NOTE: N represents the number of responses. Percentage totals may exceed $100 \%$ where multiple options were chosen. Percentages calculated based on the total number of responses to the specific question.

Nearly half $(41 \%)$ of the original research in adult and pediatric medicine represented clinical research. Health services $(21 \%)$ and QI $(19 \%)$ were the next most frequent research categories published. Publications pertaining to research in education represented $15 \%$ of all original research. Health services and QI research are growing on a relatively stable base of clinical research. These trends were similar between adult and pediatric hospital medicine. (Figure 2B) The concordance rate on the assigned research categories was $82 \%$, based on 67 publications that were independently reviewed by 2 authors. 


\begin{tabular}{|c|c|c|c|c|c|}
\hline \multirow[b]{2}{*}{ Characteristics } & \multicolumn{4}{|c|}{$\begin{array}{l}\text { Authored Peer-Reviewed } \\
\text { Publications, N (\%) }\end{array}$} & \multirow[b]{2}{*}{$P$} \\
\hline & & No & & Yes & \\
\hline Age, y & 327 & & 272 & & 0.437 \\
\hline $25-35$ & & $85(26)$ & & $72(26)$ & \\
\hline $36-45$ & & $146(45)$ & & $128(47)$ & \\
\hline $46-55$ & & $64(20)$ & & $41(15)$ & \\
\hline $56-65$ & & $30(9)$ & & $26(10)$ & \\
\hline$>65$ & & $2(1)$ & & $5(2)$ & \\
\hline Gender & 327 & & 270 & & 0.067 \\
\hline Female & & $147(45)$ & & $101(37)$ & \\
\hline Male & & $180(55)$ & & $169(63)$ & \\
\hline Faculty appointment & 301 & & 247 & & $<0.001$ \\
\hline Nonacademic & & $161(53)$ & & $63(25)$ & \\
\hline Academic & & $140(46)$ & & $184(74)$ & \\
\hline Residency & 331 & & 275 & & $<0.001$ \\
\hline Family & & $39(12)$ & & $14(5)$ & \\
\hline Internal medicine & & $184(56)$ & & $151(55)$ & \\
\hline Internal medicine (pediatrics) & & $33(10)$ & & $15(5)$ & \\
\hline Pediatrics & & $62(19)$ & & $89(32)$ & \\
\hline Other & & $13(4)$ & & $6(2)$ & \\
\hline Completed fellowship training & 332 & $19(6)$ & 277 & $47(17)$ & $<0.001$ \\
\hline Current research/career mentor & 327 & $30(9)$ & 272 & $96(35)$ & $<0.001$ \\
\hline Meet with mentor & 29 & & 88 & & 0.433 \\
\hline More often than every 6 months & & $21(72)$ & & $71(81)$ & \\
\hline Every 6 months or less & & $8(28)$ & & $17(19)$ & \\
\hline Time for research & 54 & & 153 & & $<0.001$ \\
\hline $25 \%$ or less & & $53(98)$ & & $122(80)$ & \\
\hline More than 25\% & & $1(2)$ & & $31(20)$ & \\
\hline Has funding & 54 & $8(15)$ & 156 & $60(38)$ & $<0.001$ \\
\hline
\end{tabular}

NOTE: N represents the number of responses. Percentage totals may exceed $100 \%$ where multiple options were chosen. Percentages calculated based on the total number of responses to the specific question.

There were 457 original research articles published in JHM between 2006 and early October 2013. JHM publications followed a trend similar to the publications of hospitalist-affiliated first authors from PubMed, with the majority $(47 \%)$ reflecting clinical research followed by health services $(25 \%)$ and QI $(25 \%)$. (see Supporting Figure 3 in the online version of this article)

In our review, adult medicine hospitalist authors were affiliated with 124 different universities or centers. However, 5 centers represented nearly half the publication volume. The Cleveland Clinic Foundation, University of California San Francisco (UCSF), Harvard, Northwestern, and the University of Chicago were the top producers. Fewer centers produce original research, with 66 counted in our search. Centers most prolific in producing original research are UCSF, Northwestern, University of Chicago, Harvard, and Johns Hopkins. Their combined output represented $56 \%$ of all published original published research. (see Supporting Figure $2 \mathrm{~A}, \mathrm{~B}$ in the online version of this article)

In our review, publications attributed to pediatric hospitalists were the product of 34 different centers.

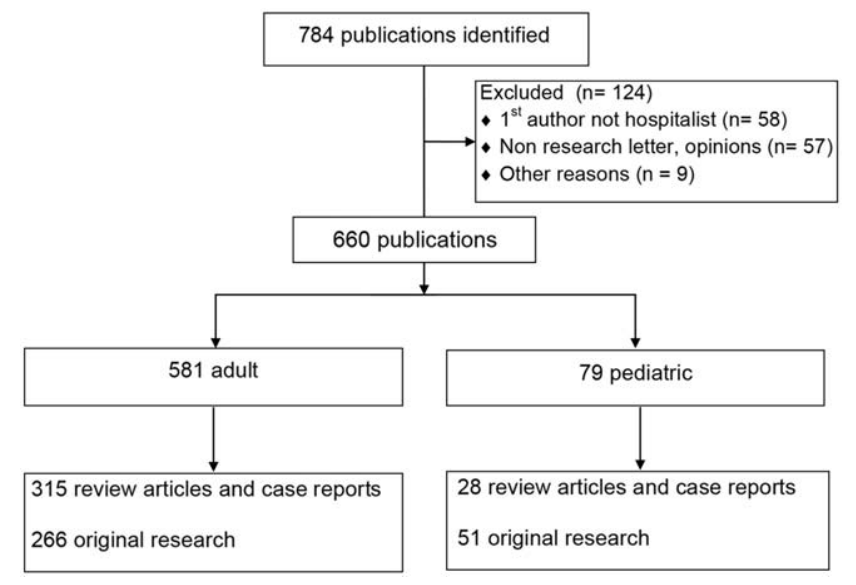

FIG. 1. Flow diagram depicting search strategy and hand-curation steps of PubMed publications for hospitalist first-author affiliation.

Cincinnati Children's Hospital Medical Center, Children's National Medical Center (Georgetown University), and the Monroe Carell Children's Hospital (Vanderbilt) were the most productive in publishing. The same centers were also the most productive in publishing original research. (see Supporting Figure 2C,D in the online version of this article)

Funding data from the 317 original research articles found in PubMed showed that $52 \%$ had funding listed for the first author and/or the work. These publications were the work of 181 different first authors, of whom $39(22 \%)$ had 1 or more funding sources specifically associated with them in the publications. The majority of these authors reported government funding $(n=24)$, followed by support from foundations $(\mathrm{n}=12)$, institutions $(\mathrm{n}=8)$, and industries $(\mathrm{n}=6)$ (see Supporting Figure 1B in the online version of this article).

\section{DISCUSSION}

Using results from both the survey and our review of publications in PubMed provided complementary information that has enriched our evaluation and reporting of the current state of research and publications in hospital medicine.

The initial growth of the field of hospital medicine can be attributed to its clinical contributions. ${ }^{17}$ However, hospital medicine faces numerous challenges in its evolution into an academic specialty. ${ }^{3}$ Job satisfaction rates among hospitalists may be falling, ${ }^{18,19}$ and pursuing intellectual outlets such as research may improve both satisfaction and productivity. ${ }^{20,21}$ Therefore, it is important to study the predictors of success for the nonclinical intellectual endeavors of hospitalists.

Across the career spectrum in academic medicine, effective mentorship has been found to be beneficial in enhancing teaching skills, productivity, and satisfaction. ${ }^{22}$ Similar to prior studies, we found that mentorship was not readily accessible, and its absence was 

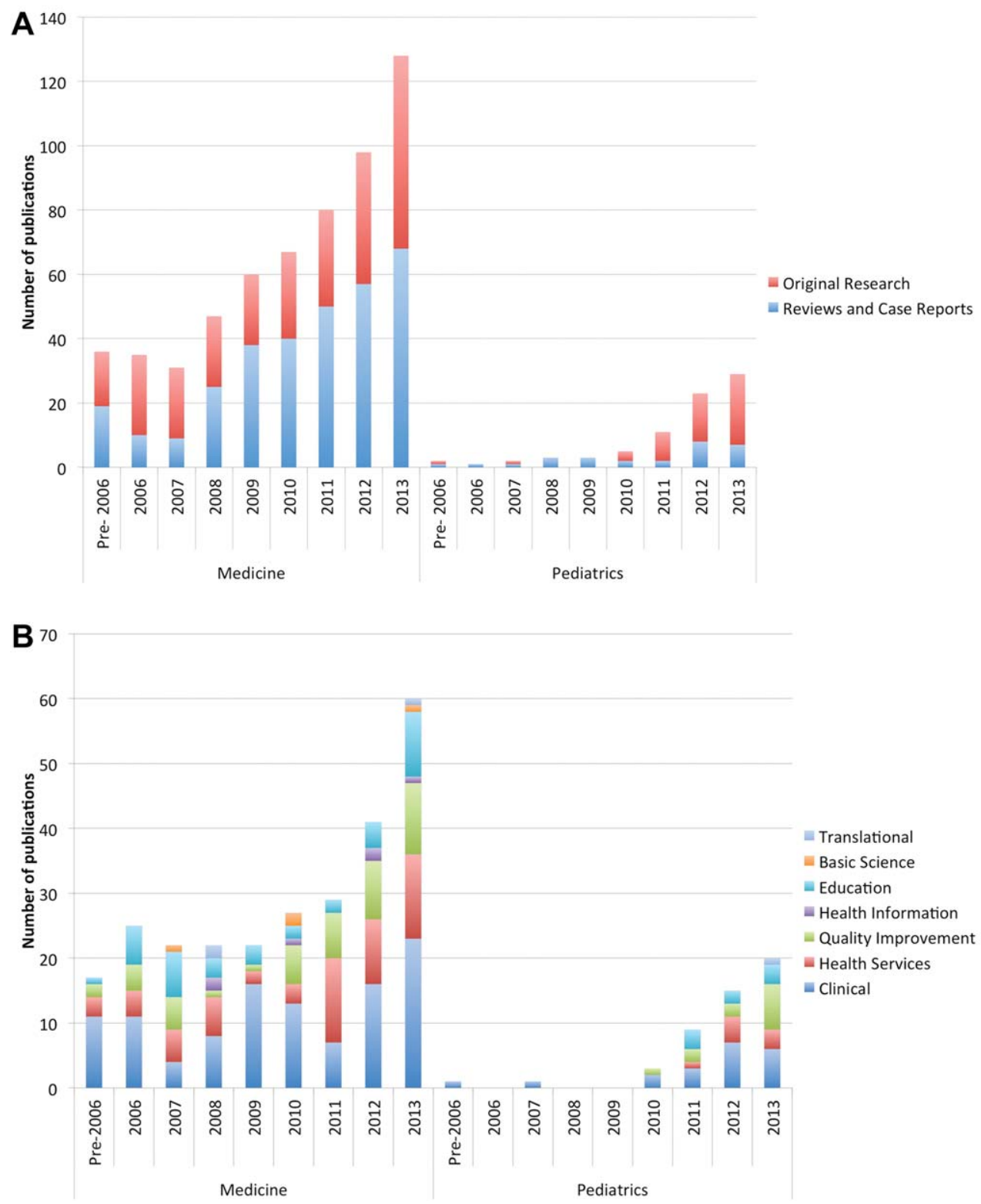

FIG. 2. (A) Trend of peer-reviewed publications by medicine and pediatric hospitalists by year. (B) Types of original research published by medicine and pediatric hospitalists. (A, B) Data searched and curated from the PubMed database.

associated with a decreased likelihood of peerreviewed publications. ${ }^{23,24}$ Hospital medicine remains a youthful specialty, with the mean age of clinicians in the $40 \mathrm{~s} .{ }^{18}$ In our survey, hospitalists aged 36 to 45 years reported the highest rates of publications and funding. If these hospitalists can be retained in the field, they may eventually serve as mentors to those entering the specialty. Strategies to provide mentorship have been described, ${ }^{25}$ and continued efforts to innovate are needed in the development of mentorship potential.

Successfully promoted hospitalists identify peerreviewed publications as a key activity that supports promotion. ${ }^{26}$ However, similar to Reid et al., ${ }^{23}$ our survey found that hospitalists reported low rates of peer-reviewed publications. Hospitalists have unique access to the inpatient population, and setting up col- laborative efforts between specialists and hospitalists, or participating in multi-institutional projects that require patient recruitment, ${ }^{27}$ may facilitate research and publication productivity. A specific emerging opportunity for this expertise is the need for collecting and identifying disease presentations to correlate with the exploding genetic data now available. ${ }^{28}$

QI research was identified from our survey results as the most frequent type of research that hospitalists were either engaged in or planned to pursue. However, based on our review of published research, the volume of QI research is surpassed by that of clinical research. Many factors contribute to this. First, an overlap between the categories of clinical and QI research may have led to lower numbers in QI. Second, there may be a lag between the interest in QI translating into publications. This may be related both 
to the dearth of QI mentorship and to the barriers in publishing QI. These barriers include increasing competition in target journals, the lack of generalizability of QI efforts, and the compressed time frames of rapid improvement cycles that differ from the slower pace of clinical research and its measurements. ${ }^{29}$ Hospitalists may also perform QI that results in scholarly output other than publications (eg, grand rounds, posters, or presentations) that we did not address. In the absence of QI publications, the systematic documentation of QI efforts in a portfolio may assist career advancement. ${ }^{30}$

The review of publications in the PubMed database through early October 2013 showed a consistent increase in the number of publications produced by hospitalist first authors. Clinical research was represented most frequently followed by health services and QI research. The predominance of clinical research parallels the large clinical role of hospitalists; however, the diversity of research categories represented reflects the growing penetration and involvement of hospitalists in the arenas of QI, health services, and education. Although our search identified fewer pediatric hospitalist articles, pediatric hospitalist literature is also on the rise. There are other indicators of the enthusiasm for research among pediatric hospitalists, as nearly half the respondents in our survey who are currently engaged in research and nearly a third who had successfully published or had funding support were trained in pediatrics.

Publications by first authors who were hospitalists or affiliated with hospital medicine represented the effort of more than 100 institutions, implying a widespread engagement in hospital medicine-related scholarship. However, fewer centers produce original research, and over half the original research output is the product of 8 centers. Strategies to select and support person-job fit, ${ }^{31}$ availability of mentorship, the presence of existing infrastructure, funding, and departmental priorities are all likely to affect an institution's publication productivity. To emulate the success of these centers, a closer study of the strategies they employ ${ }^{5}$ would be instructive for the broader hospitalist community.

Although our survey data showed that the presence of funding is associated with success in publishing, the percentage of hospitalists who report funding both from the survey and PubMed publication reports is $<25 \%$. This underscores the need for innovations that help hospitalists obtain support and incentives for their work.

This study has limitations. A survey is a crosssectional snap shot, and associations do not imply causation. Survey response rates have been falling, ${ }^{32}$ and our convenience sampling without incentives engendered a low response rate. This response rate is similar to that of other surveys administered through SHM (SHM membership and marketing data, October 2013). Although statistical significance is pre- sented, the differences may not be generalizable given the low response rate. We cannot quantify all responder biases or comment on how the membership fee to SHM may affect the sample cohort. The demographics of our respondents parallel that of the SHM membership base in age and gender. However, 25\% of our respondents were trained in pediatrics, whereas only $4.3 \%$ of the SHM membership base is pediatrics trained (SHM membership and marketing data, October 2013). We did not inquire about contributions from job dissatisfaction to the lack of participation in research activities, and this may represent an area for further research.

The search methodology used in this study is likely to under-report hospitalist-related research, because collaborative publications in which the lead author is not a hospitalist were not included. Furthermore, many hospitalists are associated with centers that do not have a hospitalist or hospital medicine title or department, and our search terms would have missed the publications stemming from these centers. Pediatric hospitalist literature is likely to be further underrepresented, as centers may not have separate pediatric hospitalist departments.

The assignment of each publication into a research category was based on definitions found in the literature. However, this designation ultimately remains a subjective process that may introduce bias.

Although the initial growth spurt of hospital medicine can be attributed to its clinical success, the increase in hospital medicine-led peer-reviewed publications in increasingly diverse domains provides evidence that supports the field's concomitant academic and scholarly maturation. Research into factors that impede or inspire hospitalists to participate in research, innovations that provide mentorship and funding for the specific interests of hospitalists, and the emulation of strategies employed by centers productive in publications are required to successfully foster the multidimensional growth of the field.

\section{Acknowledgements}

The authors thank Dr. Antoinette Laskey for her mentorship in survey development, Elaine Bammerlin for copyediting assistance, and the Society of Hospital Medicine members for taking the survey.

Disclosures: An Dang Do, MD, PhD, completed the major part of this work as a Morris Green Scholar at Indiana University School of Medicine. An N. Dang Do, MD, PhD, and Amy M. Munchhof, MD, PhD, contributed equally to this work. Areeba Kara, MD, is supported by a grant from the Methodist Health Foundation and by award number T15OC000047 from the Office of the National Coordinator for Health Information Technology, Office of the Secretary, US Department of Health \& Human Services. The content is solely the responsibility of the authors and does not necessarily represent the official views of the Office of the National Coordinator For Health Information Technology, Office of the Secretary, US Department of Health \& Human Services, or the National Institutes of Health.

\section{References}

1. Wachter R, Goldman L. The emerging role of "hospitalists" in the American health care system. N Engl J Med. 1996;335(7):514-517.

2. Kralovec PD, Miller JA, Wellikson L, Huddleston JM. The status of hospital medicine groups in the United States. J Hosp Med. 2006;1(2): 75-80. 
3. Flanders SA, Centor B, Weber V, McGinn T, DeSalvo K, Auerbach A. Challenges and opportunities in academic hospital medicine: report from the Academic Hospital Medicine Summit. J Hosp Med. 2009; 4(4):240-246.

4. Sehgal NL, Sharpe BA, Auerbach AA, Wachter RM. Investing in the future: building an academic hospitalist faculty development program. J Hosp Med. 2011;6(3):161-166.

5. Flanders SA, Kaufman SR, Nallamothu BK, Saint S. The University of Michigan Specialist-Hospitalist Allied Research Program: jumpstarting hospital medicine research. I Hosp Med. 2008;3(4):308-313.

6. Howell E, Kravet S, Kisuule F, Wright SM. An innovative approach to supporting hospitalist physicians towards academic success. $J$ Hosp Med. 2008;3(4):314-318.

7. Zimbric G, Srivastava R. Research in pediatric hospital medicine: how research will impact clinical care. Curr Probl Pediatr Adolesc Health Care. 2012;42(5):127-130.

8. Harrison R, Hunter AJ, Sharpe B, Auerbach AD. Survey of US academic hospitalist leaders about mentorship and academic activities in hospitalist groups. J Hosp Med. 2011;6(1):5-9.

9. Society of Hospital Medicine website. Available at: http://www.hospitalmedicine.org. Accessed February 25, 2013.

10. US National Library of Medicine website. MEDLINE/PubMed data element (field) descriptions. Available at: http://www.nlm.nih.gov/ bsd/mms/medlineelements.html. Accessed October 30, 2013.

11. American Educational Research Association website. Available at: http://www.aera.net/EducationResearch/WhatisEducationResearch/tab id/13453/Default.aspx. Accessed October 30, 2013.

12. National Institutes of Health website. Glossary of NIH terms. Available at: http://grants.nih.gov/grants/glossary.htm. Accessed February 26, 2013.

13. US National Science Foundation website. National Center for Science and Engineering Statistics. Definitions of research and development: an annotated compilation of official sources. Available at: http:// www.nsf.gov/statistics/randdef/fedgov.cfm. Accessed February 26, 2013.

14. Lohr KN, Steinwachs DM. Health services research: an evolving definition of the field. US National Library of Medicine website. National Institutes of Health. Available at: http://www.ncbi.nlm.nih.gov/pmc/ articles/PMC1430351. Accessed February 26, 2013.

15. Centers for Medicare and Medicaid Services website. Outcome measures. Available at: http://www.cms.gov/Medicare/Quality-InitiativesPatient-Assessment-Instruments/HospitalQualityInits/OutcomeMeasu res.html. Accessed August 22, 2013.

16. Journal of Hospital Medicine. Available at: http://onlinelibrary.wiley. com/journal/10.1002/(ISSN)1553-5606/homepage/ProductInformation.html. Accessed October 30, 2013.

17. Peterson MC. A systematic review of outcomes and quality measures in adult patients cared for by hospitalists vs nonhospitalists. Mayo Clin Proc. 2009;84(3):248-254.
18. Hinami K, Whelan CT, Miller JA, Wolosin RJ, Wetterneck TB; Society of Hospital Medicine Career Satisfaction Task Force. Job characteristics, satisfaction, and burnout across hospitalist practice models. J Hosp Med. 2012;7(5):402-410.

19. Glasheen JJ, Misky GJ, Reid MB, Harrison RA, Sharpe B, Auerbach A. Career satisfaction and burnout in academic hospital medicine. Arch Intern Med. 2011;171(8):782-785.

20. Arora V, Fang MC, Kripalani S, Amin AN. Preparing for "diastole": Advanced training opportunities for academic hospitalists. J Hosp Med. 2006;1(6):368-377.

21. Meltzer D, Manning WG, Morrison J, et al. Effects of physician experience on costs and outcomes on an academic general medicine service: results of a trial of hospitalists. Ann Intern Med. 2002;137(11): 866-874.

22. Sambunjak D, Straus SE, Marusic A. Mentoring in academic medicine: a systematic review. JAMA. 2006;296(9):1103-1115.

23. Reid MB, Misky GJ, Harrison RA, Sharpe B, Auerbach A, Glasheen JJ. Mentorship, productivity, and promotion among academic hospitalists. J Gen Intern Med. 2011;27(1):23-27.

24. Wiese J, Centor R. The need for mentors in the odyssey of the academic hospitalist. J Hosp Med. 2011;6(1):1-2.

25. Abougergi MS, Wright SM, Landis R, Howell EE. Research in progress conference for hospitalists provides valuable peer mentoring. J Hosp Med. 2011;6(1):43-46.

26. Leykum LK, Parekh VI, Sharpe B, Boonyasai RT, Centor RM. Tried and true: a survey of successfully promoted academic hospitalists. J Hosp Med. 2011;6(7):411-415.

27. Wasserman R, Serwint JR, Kuppermann N, Srivastava R, Dreyer B. The APA and the rise of pediatric generalist network research. Acad Pediatr. 2011;11(3):195-204.

28. Bennett SN, Caporaso N, Fitzpatrick AL, et al. Phenotype harmonization and cross-study collaboration in GWAS consortia: the GENEVA experience. Genet Epidemiol. 2011;35(3):159-173.

29. Shojania KG, Levinson W. Clinicians in quality improvement: a new career pathway in academic medicine. JAMA. 2009;301(7):766-768.

30. Taylor BB, Parekh V, Estrada CA, Schleyer A, Sharpe B. Documenting quality improvement and patient safety efforts: the quality portfolio. A statement from the Academic Hospitalist Taskforce [published online ahead of print June 27, 2013]. J Gen Intern Med. doi: 10.1007/ s11606-013-2532-z.

31. Hinami K, Whelan CT, Miller JA, Wolosin RJ, Wetterneck TB. Person-job fit: an exploratory cross-sectional analysis of hospitalists. J Hosp Med. 2012;8(2):96-101.

32. Cull WL, O'Connor KG, Sharp S, Tang S-FS. Response rates and response bias for 50 surveys of pediatricians. Health Serv Res. 2005; 40(1):213-226. 